\title{
DEVELOPING A MODEL FOR INNOVATION IN UNDERGRADUATE ENGINEERING EDUCATION - THE SYSTEMATIC INTEGRATION OF HUMAN-CENTERED DESIGN
}

\author{
W. Patrick Neumann., Judy Village, Michelle Bristow, and Filippo A. Salustri \\ Department of Mechanical and Industrial Engineering, Ryerson University, Toronto, Canada \\ Email: pneumann@ryerson.ca
}

\begin{abstract}
The goal of this project was to integrate more human factors and human centered design content into mechanical engineering courses. Using the Six Sigma (DMAIC) approach, we defined HF broadly as any course content aspects related to humans. We measured the HF content of courses based on interviews with 38 instructors. All but six courses had less than 10 hours of $H F$ content and only one course taught students how to use HF aspects to improve design. Twelve courses were targeted for improvement and of these, seven instructors agreed to integrate HF content. The observed rate of change is modest and ongoing support would be needed to foster more substantial development. We recommend a more nuanced 4-level model for defining $H F$-related coursework. We also discuss the barriers to integrating $H F$ and suggest some countermeasures.
\end{abstract}

Keywords:

Engineering education

Human factors

Human centered design

\section{INTRODUCTION}

Attention to human factors in undergraduate engineering design training is inexplicably lacking in Canadian programs, despite the fact that humans are intimately involved in the manufacture, installation, routine use, maintenance, and decommissioning of every engineering design product. The lack of understanding and attention to human abilities, needs, and limitations, is an integral part of most engineering design failures. These failures may have trivial consequences like the inability of a user to set the clock on an appliance, or they may compromise the safety of people, such as in cases of work-place design where the costs of design related ill health are on par with all cancers combined. Without an ability to understand the "human in the system" in engineering design contexts, engineering students are poorly equipped to follow the paramount ethical requirement of their own professional code. Engineers urgently need training that includes attention to human aspects and human interaction with the systems they are designing. Systems designed with people in mind will be safer, more effective, and more desirable designs for the customer. Incorporating human factors (HF) into engineering poses a huge untapped contribution to innovation potential in engineering design.

\section{OBJECTIVE}

This paper reports on a pilot study exploring the application of a systematic, six-sigma DMAIC (Define, Measure, Analyse, Implement, Control), approach to integrating human factors into a mechanical engineering program.

\section{METHODS}

This study uses the Six-Sigma DMAIC (Define, Measure, Analyse, Improve, Control) methodology. We established an operational definition for HF that can be quantified for a given course and program. For the purpose of this study, human factors was defined very broadly as any aspect of the course related to humans. We collected course descriptions and course content from each course taught in the Department of Mechanical Engineering at Ryerson University. We then conducted interviews with instructors in the department. Each instructor was asked whether their course has any human related content and how this relates to the course material? If they responded positively, we measured by asking them to quantify the number of lecture hours and number of questions on tests, assignments and projects to determine the percentage of the final grade that had human related content. This approach is consistent with the CEAB methods that evaluate the amount of content in Canadian coursework. We also asked each instructor to describe the human content with examples and to discuss the facilitators and barriers of supplementing the course with human related content. Interviews were audio recorded, and the researcher also supplemented the recordings with written notes. 
We then analyzed this data, along with the course outlines, to identify likely candidate courses that could be supplemented with HF content. The research team reviewed the interviews, notes and course outlines and brainstormed ideas for new possible HF supplements to each course. The research team prioritized the candidate courses based on whether they were being offered in the next semester, and whether the instructor indicated some willingness to incorporate HF material into the lectures and assignments. We then contacted instructors of prioritized courses to engage in improvement actions. We supplied each instructor with the list of possible HF improvement ideas and offered assistance with developing materials for their upcoming semester. Materials could include the addition of HF information, exercises or lab assignments, examples to support core content (e.g. calculating heat loss for a human in water), or the addition of HF related parameters (e.g. Human heat perception supporting HVAC design). The intent was to supplement not supplant the core curriculum content in ways that make sense to the instructor and do not add to instructor burden. The researchers and instructors collaborated to develop these new HF modules.

In the currently on-going control phase of the project we will update the quantitative indicators as well as conduct short interviews with instructors exploring their experience of the improvement approach and of delivering the new HCD modules. This information will allow us to improve the change model for subsequent application in other engineering programs.

\section{RESULTS}

We collected course outlines and course content for all 39 courses offered in the Mechanical Engineering program. Interviews were successfully conducted with 38 of the 39 professors $(97 \%)$. Interviews took approximately 30 minutes each. Of the 39 courses, six had no discernable content related to human factors or humans in the course. The remaining 33 courses have some human-related material, ranging from 15 minutes upward. Figure 1 shows the number of lecture hours with human content in the 39 courses. All but six courses had less than 10 lecture hours related to human aspects. Only one course, "Introduction to Engineering Design" had explicit human factors content that provided students with specific ways to integrate human factors into engineering design. The next five courses with the most human-related content did not provide engineers with explicit HF knowledge or skills to apply to design problems. In the course "Environmental Impact of Thermal Systems", the role of the human was implicit in that they cannot be separated from the impact of thermal systems.

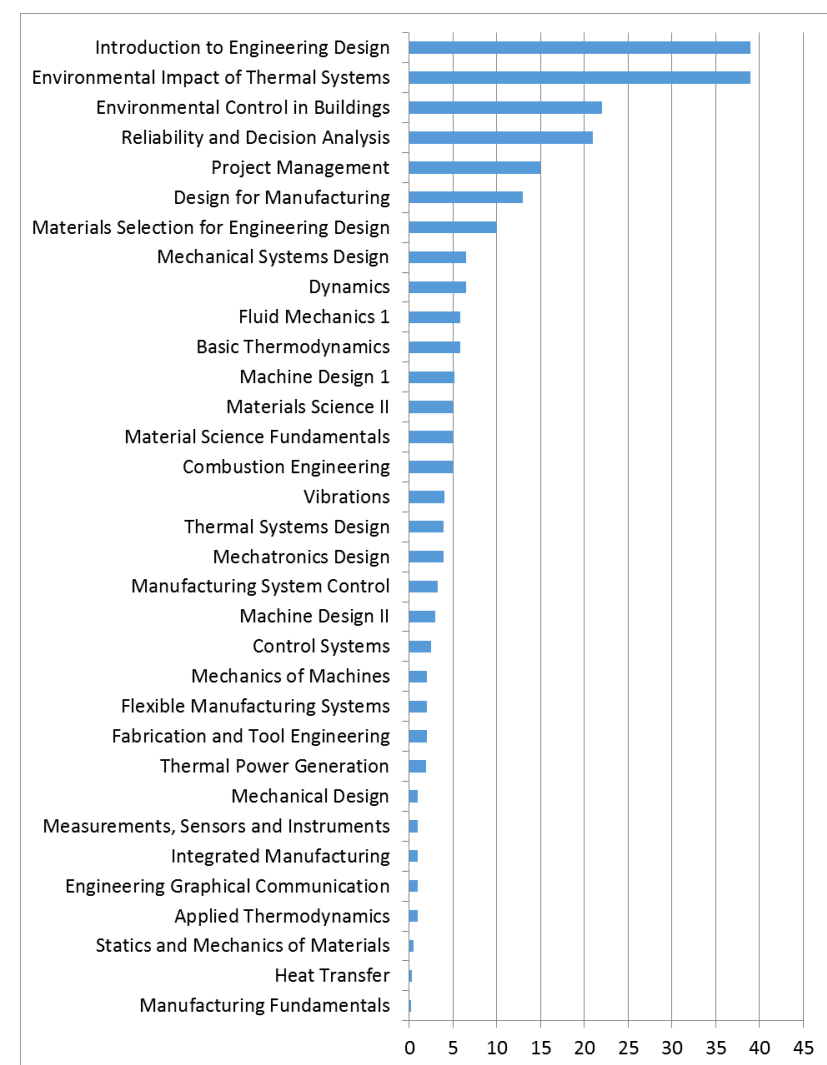

Fig. 1. Number of lecture hours of "human" content measured in each mechanical engineering course

In "Environmental Control in Buildings", technical design decisions are driven by human needs, but there was only a small amount of information regarding design for human comfort and health. In "Reliability and Decision Analysis", the human content was indirect in that humans are assumed to be involved in the decision-making process. However, no HF information was taught regarding human information processing or decisionmaking or error-proofing. In "Project Management", the human-related aspects refer to the project manager as a human working in an organization, involved in teamwork and interpersonal skills. In "Design for Manufacturing", there was some HF content related to assembly/disassembly, maintainability and customer needs and marketing.

Regarding "human" content in student evaluations (i.e. assignments, projects, exams), fifteen courses had no evaluation components to test the understanding or application of human factors in the course. The remaining 24 courses had some evaluation component ranging from $1.88 \%$ upwards that relates to human examples or realworld applications involving humans. In 18 of the 24 courses the human content in the final grade was less than $20 \%$. In most cases the human element was used to set the context or to test the practical application of course concepts. Table 1 provides examples of human content 
found in some courses, and also shows courses where these concepts were taught. HF concepts included human safety (including regulations and codes), human error, operator access, maintainability and assembly, design against failure, and human machine interface. Content was missing from all but the introductory design course (which is co-taught by a professor with a human factors background) related to how to design for human capabilities and limitations (eg. human anthropometrics, strength, physical and cognitive demands, perception capabilities, and tolerance to environmental stresses).

Table 1: Sample human factors concepts being taught and accompanying courses

\begin{tabular}{|c|c|}
\hline Example Concepts & Example Courses \\
\hline $\begin{array}{l}\text { Human safety } \\
\text { (regulations, codes) }\end{array}$ & $\begin{array}{l}\text { Machine Design } \\
\text { Flexible Manufacturing } \\
\text { Systems } \\
\text { Design for Manufacturing } \\
\text { Thermal Systems Design }\end{array}$ \\
\hline Human Error & $\begin{array}{l}\text { Measurements, Sensors and } \\
\text { Instruments } \\
\text { Reliability and Decision } \\
\text { Analysis } \\
\text { Manufacturing Fundamentals } \\
\text { Fabrication and Tool } \\
\text { Engineering }\end{array}$ \\
\hline $\begin{array}{l}\text { Operator access, } \\
\text { cleanability, } \\
\text { maintainability }\end{array}$ & $\begin{array}{l}\text { Thermal Systems Design } \\
\text { Design for Manufacturing }\end{array}$ \\
\hline $\begin{array}{l}\text { Design against } \\
\text { failure }\end{array}$ & $\begin{array}{l}\text { Thermal System Design } \\
\text { Manufacturing System Control }\end{array}$ \\
\hline $\begin{array}{l}\text { Impact on human } \\
\text { health and } \\
\text { environment }\end{array}$ & Thermal Power Generation \\
\hline Human comfort & $\begin{array}{l}\text { Applied Thermodynamics } \\
\text { Environmental Control in } \\
\text { Buildings }\end{array}$ \\
\hline $\begin{array}{l}\text { Human machine } \\
\text { interface }\end{array}$ & $\begin{array}{l}\text { Mechatronics Design } \\
\text { Fabrication and Tool } \\
\text { Engineering }\end{array}$ \\
\hline
\end{tabular}

Twelve courses were targeted as first priority courses for improvement based on the course running in the next semester, and the course content being appropriate for HF inclusion. For each of the 12 courses, the research team brainstormed a list of suggested HF content, specific to the curriculum and content as explained by the instructor teaching the course. The course "Manufacturing Fundamentals" will be used as an example to illustrate the HF content ideas that were suggested to supplement the course. The course provides an overview of the manufacturing processes and methods, emphasizing an understanding of the physical fundamentals such as:

- manufacturing industries, systems, processes, production systems, attributes of manufactured products

- engineering metrology

- metal-casting

- material removal processes

- metal working processes

- shaping processes for plastics

The HF-related content in the Manufacturing Fundamentals course was measured as 0.25 hours in one lecture on the topic of human error and systematic mechanical error. The following eight suggestions were provided to the professor for increasing HF related content:

1. Usability issues related to the design project such as anthropometric data of the hand, clearances, grip strength, range of joint motion, visual aspects, tactile feedback - add to design brief, include lecture notes and a rubric for assessment of student project for human factors

2. In metrology lab students learn to use various instruments. Instructions could be added to the lab manual for the "feel" or "feedback" aspects of using the instruments.

3. A comparison of manufacturing processes for different human applications. Which manufacturing processes, for example (of the ones covered in class) would be the best option for making a bone implant? A prosthetic foot? A walker?

4. A look-ahead slide in the last lecture to design for manufacturability - maybe an opportunity to discuss human variability (vs. reliability). Include a unit on design for manufacturability.

5. Reach and fit issues with manufacturing, awkward use, poor control design.

6. Design of emergency controls.

7. Feedback and process awareness.

8. Metrology and the usability of the measurement tools.

In consultation with the instructor, it was decided that HF would be incorporated into the main design project where the student teams design and make a small hand-held machine with which they then compete against other teams in a timed trial to complete a task. The instructor wanted HF aspects incorporated that would improve the usability of the machine during the competition. The researchers provided guidelines for the design, installation and use of machine tools, anthropometric data for hand clearance and access openings, grasp diameters, torque 
and separation for fingers and hands, hand dimensions, hand strength data, and ranges of joint mobility. The students were provided this information by the authors and the instructor guided students to incorporate the HF data into their design. They would then be evaluated in the marking of the project for the HF inclusion. An "Ergonomics of Machine Design Marking Grid" was also supplied to the instructor to assist in grading the HF aspects of the design.

Of the 12 courses targeted for HF improvement, seven professors agreed to include HF information, and materials were provided to these professors, similar to the example provided above. For the five professors that declined the improvement ideas, the main barrier was lack of time, or that the course was already packed for course content.

During the interviews, one professor who was currently teaching a course on combustion engineering, agreed to include a scientific publication on preventing laproscopic explosions to:

- Test understanding of the factors leading to explosions; and

- $\quad$ Determine ability to use this understanding to prevent explosions

Comments from the professor about the inclusion of human-related examples were that:

\section{"The students loved it. It was the most compelling lecture in the course to date. \\ The students are accustomed to thinking about applying the combustion fundamentals to vehicles, power generation, and heating, and I think this was a welcome and surprising change."}

At this time we are in the process of evaluating the outcomes of the inclusion of HF related material into the seven courses this semester. Qualitative analysis of the facilitators and barriers to incorporating HF aspects into the mechanical engineering curriculum were gathered from interviews with the 39 instructors. The benefits, as illustrated with the quote above, are that human aspects can make the course more interesting and relevant for students, and that they can provide alternative means to explain a concept. There was recognition by several instructors that HF is becoming more important in engineering design, especially in certain industries such as aviation, nuclear power, and health care. Some instructors also saw HF as a means to help build connections with industry. There was recognition that the inclusion of HF improves the overall design.

\section{DISCUSSION}

CEEA15; Paper \#142

McMaster University; May 31 - June 3, 2015
This pilot study has demonstrated the feasibility of using a Six-Sigma DMAIC approach to help structure engineering curriculum development work. The observed rate of change is modest and ongoing support would be needed to foster more substantial development. This is consistent with organisational change research suggesting that 2-3 years is a common requirement for sustainable developmental change projects. This current report is at the 1-year point with much of the time being front-end preparatory evaluation work and only one semester of HF intervention. This project has revealed a number of limitations and barriers to the change process, which are discussed below.

With regards to the "Define" stage of DMAIC, the initial work took a very broad definition to "Human Factors" and included any materials that were related to HF aspects - even if those were not directly aimed at teaching knowledge about humans-in-the-system. The "Decision Making" course for example is implicitly related to human decision making but focused on rational mathematical approaches without addressing any of the factors that affect real human decision making: bias, time pressure, fatigue, information processing capabilities etc. On reflection, we would recommend a more nuanced approach to identifying and measuring HF content in the program based on a four level schema:

Level 0: HF Relatable content - The course content can be related to human aspects but this connection is currently unrealised or left as implicit. An example here might be an HVAC course that focuses on the techniques of establishing a certain environmental setting without addressing human comfort, human heat balance, or human response to humidity or cold.

Level 1: Human as a System - The course uses a human example to motivate learning about a basic science principle. In such cases the human is considered as a "machine", but the effects on the human are not in focus instead the human is the object used to illustrate a basic engineering principle. The laproscopic example developed in this project for the course on combustion engineering illustrates the human as a system. This level has the potential to build awareness about humans and how the principles of engineering science manifest in the human body.

Level 2: Knowledge of Human Factors - Explicit knowledge about humans is provided which illuminates how the human interacts with and is affected by the system. This includes specific information about human perception, cognition, and motor capabilities in the context of their interaction with the system. 
Level 3: Human Centred Design (HCD) Skills - At this level students are required to integrate HF information into their design process and to include human needs and limitations as part of their design criteria. At this level, students are designing with the knowledge and use of data about human capabilities and limitations to improve design.

While Level $3 \mathrm{HCD}$ is the goal of the initiative being described here, levels 1 and 2 can both serve to help engineers understand the human in the system and how engineering can benefit and support humans. In our examination, with the exception of one course in introductory engineering design, no other course reached level 3 and few courses were addressing levels 1 or 2 as measured at the start of the change project.

The qualitative aspects of the initial interviews and discussions during the ongoing change process revealed a number of barriers to change. While these are generally consistent with the change management literature we will address some of the key issues here and propose countermeasures.

Barrier 1: "Courses are overloaded". This was a common theme; that courses have been filled with material that is considered traditional for the topic. This issue needs to be tackled head on. If engineering students are to understand the human in the system, to design safe and effective systems, then some space must be made for this content. Since other barriers (see below) pose limits on instructors, incentives must be applied. Incentives could come from the department, CEEA support, or even CEAB mandate to help motivate the change and make the difficult decisions regarding content. We note that, for those professors who chose to take up some HF aspects in their course, they were easily able to "make space" for the new material.

Barrier 2: "Time \& workload limits". This issue is also about priorities. If the reward structure and leadership of the department does not support the change process actively then this barrier will dominate. The other mechanism to minimise this barrier is the availability of support resources making it as easy as possible for the instructor to include HF and HCD in their teaching. We propose, for example, creating a catalogue of materials related to common engineering principles that could be taken up and applied readily by an instructor.

Barrier 3: "Lack of Knowledge". This frequently mentioned barrier needs to be addressed with support including the provision of materials, a selected book chapter, coaching, and possibly workshops to familiarise instructors with relevant human aspects. There may also be a misunderstanding around the complexity of human factors - where most human aspects can be understood and addressed at a level that is much less technologically complex then the underlying engineering issue being taught.

Barrier 4: "Lack of motivation" - This finding was based more on observation and inference than specific comments from instructors. It is also consistent with other studies of change processes and the larger discussion of organisational change. Motivation might be increased by adjustments to the reward structure, raising the profile of successful improvement projects, and via leadership support of the initiative. Motivation can also depend on reducing the "costs" of engaging in change - possible with the support strategies listed above. Another low-cost strategy to initiate change in including $\mathrm{HF}$ at level 3 would be via the capstone design projects. If a HF element could be included in the capstone project - requiring students to consider human outcomes and effects of their design choices, this would provide opportunities for both professors and students to consider HF in design. This could be supported with a general HF in Design type checklist and rubric, which can provide guidance to both parties. We suggest targeting the capstone projects since they have a different dynamic and are not owned by a single professor.

\section{CONCLUSIONS}

This project has demonstrated that some instructors were willing and interested to integrate more HF into course content and saw the value and advantages for their students. Although there were resource implications for providing the HF content, several instructors were willing to spend additional time to ensure the material was integrated into their courses. A follow-up evaluation underway will measure the increase in HF content in the seven courses where instructors were willing to incorporate HF content.

\section{Acknowledgements}

The authors graciously acknowledge the financial support of the Dean's Teaching Fund, Faculty of Engineering and Architectural Sciences, Ryerson University. We also thank the Chair of the Department of Mechanical and Industrial Engineering, Ryerson University, for his support, as well as all the instructors who gave of their time to work with us. 